06

\title{
Определение электродинамических характеристик стеклонаполненных пластмасс в миллиметровом диапазоне частот
}

\author{
() Н.С. Князев, А.И. Малкин, В.А. Чечеткин \\ Уральский федеральный университет им. Б.Н. Ельцина, Екатеринбург, Россия \\ E-mail: n.s.kniazev@urfu.ru
}

Поступило в Редакцию 6 ноября 2020 г.

В окончательной редакции 6 ноября 2020г

Принято к публикации 27 ноября 2020 г.

\begin{abstract}
Исследована возможность использования электродинамических характеристик стеклонаполненных пластмасс, измеренных в низкочастотном диапазоне, для проектирования радиопрозрачных укрытий устройств, работающих в диапазоне частот $78-81 \mathrm{GHz}$. Проведено сравнение экспериментальных результатов измерения образцов с результатами моделирования. Оценена возможность применения для радиопрозрачного укрытия изделий из материала отечественного производителя.
\end{abstract}

Ключевые слова: стеклонаполненные пластмассы, диэлектрическая проницаемость, электродинамические параметры, электродинамическое моделирование.

DOI: 10.21883/PJTF.2021.05.50678.18610

Стеклонаполненные полибутилентерефталаты используются в автомобильной промышленности для радиопрозрачных укрытий в диапазоне $77 \mathrm{GHz}$ (см., например, работу [1], где в качестве подобного укрытия применен 30\% наполненный стекловолокном материал BASF-Ultradur B4300G6 LS sw 15073). Измерение диэлектрической проницаемости материала непосредственно на рабочих частотах разрабатываемых изделий требует дорогостоящего оборудования и соответствующей квалификации персонала. Помимо рассмотрения методики определения диэлектрической проницаемости на более низких частотах с последующей интерполяцией измеренного значения диэлектрической проницаемости в область рабочих частот разрабатываемых устройств в задачу нашего исследования входила оценка возможности применения для радиопрозрачного укрытия изделий из материала отечественного производителя. Поэтому сравнительные измерения выполнены на двух экспериментальных образцах: 1) образец стеклонаполненного термостабилизированного полибутилентерефталата Технотер А-СВ30-Т-20, рекомендуемого производителем для изготовления методом литья под давлением изделий конструкционного, электротехнического и бытового назначения, применяемых в машиностроении, электротехнике, автомобилестроении, радиотехнике, приборостроении, а также для ручек в газовом оборудовании [2]; 2) контрольный образец радиопрозрачного укрытия радара одного из европейских производителей.

Количественное сопоставление примесного состава исследуемых образцов было выполнено методом атомно-эмиссионной спектроскопии. Пробы исследуемых образцов помещались в платиновые тигли и озолялись при температуре $700^{\circ} \mathrm{C}$ в муфельной печи. Навеска остатка смешивалась с графитовым порошком так, что его массовая доля составляла $2 \%$, далее в смесь вво- дился фторид висмута (массовая доля 5\%). Полученная смесь помещалась в кратеры графитовых электродов, между которыми возбуждался дуговой разряд постоянного тока силой $12 \mathrm{~A}$. Атомно-эмиссионные спектры регистрировались спектрометром PGS-2+MAЭС. Для градуировки использовались стандартные образцы графита СОГ-21 ГСО 4519-СО 4520. Результаты анализа приведены в таблице.

Анализ примесного состава указывает на разницу в материалах использованного для наполнения полибутилентерефталата оптического волокна. Так, при изготовлении отечественного материала исходя из состава примесей использовано алюмоборосиликатное стекло общего назначения (тип Е).

Электродинамические характеристики (диэлектрическая проницаемость, тангенс угла диэлектрических потерь) стеклонаполненного термостабилизированного полибутилентерефталата имеют большую зависимость от концентрации стекловолокна [3]. В литературе исследуемый частотный диапазон для стеклонаполненных пластиков не превышает нескольких $\mathrm{GHz}$ [4]. Производители в технических условиях нормируют диэлектрическую проницаемость для частот, не превышающих нескольких сотен $\mathrm{MHz}$.

Для исследования диэлектрической проницаемости и тангенса угла диэлектрических потерь применялась методика, основанная на пересчете значений матрицы рассеяния, измеренной при помощи векторного анализатора цепей [5]. Коэффициенты матрицы рассеяния измеряются для образца, помещенного непосредственно в используемую линию передачи. Для измерения используются волноводы стандартов WR62, WR42 и WR22, перекрывающие частотный диапазон от 12 до $50 \mathrm{GHz}$.

На рис. 1 изображена линия передачи с помещенным внутрь нее образцом толщины $l_{s}$. 
Результаты анализа образцов

\begin{tabular}{l|c|c|c|c|c}
\hline \multirow{2}{*}{\multicolumn{1}{c|}{ Образец }} & \multicolumn{5}{|c}{ Массовая доля оксида в золе пластмасс $W, \%$} \\
\cline { 2 - 6 } & $\mathrm{Al}_{2} \mathrm{O}_{3}$ & $\mathrm{~B}_{2} \mathrm{O}_{3}$ & $\mathrm{CaO}$ & $\mathrm{MgO}$ & $\mathrm{Fe}_{2} \mathrm{O}_{3}$ \\
\hline $\begin{array}{l}\text { Образец радиопрозрачного } \\
\text { укрытия промышленного радара } \\
\text { Технотер А-СВ30-Т-20 }\end{array}$ & 15 & 0.012 & 25 & 3.6 & 0.26 \\
\end{tabular}

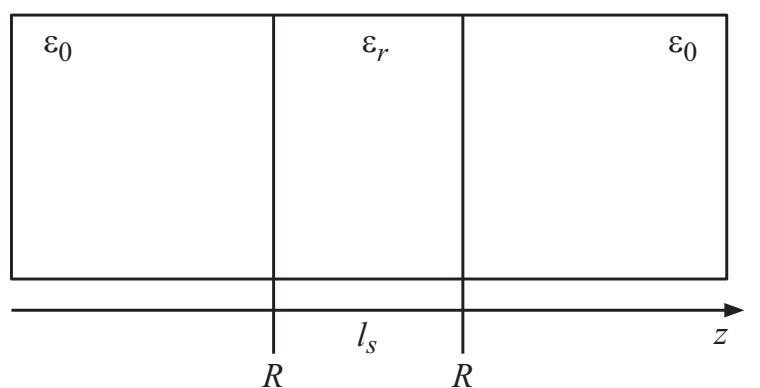

Рис. 1. Размещение образца в линии передачи: $\varepsilon_{0}-$ комплексная диэлектрическая проницаемость среды, заполняющей волновод, $\varepsilon_{r}-$ комплексная диэлектрическая проницаемость исследуемого образца, $R$ - положение опорной плоскости измерения для векторного анализатора цепей, $l_{s}$ - толщина исследуемого образца.

Пересчет измеренных коэффициентов матрицы рассеяния в значение комплексной диэлектрической проницаемости происходил с применением математического алгоритма Nicolson-Ross-Weir.

Сравнение результатов измерения диэлектрической проницаемости материалов Технотер А-CB30-Т-20 и образца радиопрозрачного укрытия радара одного из европейских производителей в диапазоне частот от 8 до $18 \mathrm{GHz}$ показало, что оба образца имеют одинаковый спектр диэлектрической проницаемости. Результаты измерения диэлектрической проницаемости образцов Технотер А-СВ30-Т-20 представлены на рис. 2.

Из полученных данных следует, что проницаемость исследуемого пластика имеет постоянную частотную зависимость с отклонением от среднего значения, не превышающим 7\%. С учетом погрешности измерительной системы $5 \%$ можно считать, что среднее значение диэлектрической проницаемости в исследуемом диапазоне частот постоянно и равно 3.

Согласно теории механизма возникновения диэлектрической проницаемости, в диапазоне частот от 1 до $1000 \mathrm{GHz}$ основным типом взаимодействия является дипольное, что подразумевает монотонное уменьшение диэлектрической проницаемости с ростом частоты. Таким образом, в рассматриваемом диапазоне частот значение диэлектрической проницаемости, измеренное в диапазоне до $50 \mathrm{GHz}$, должно совпадать со значением диэлектрической проницаемости материала в диапазоне
$78-81 \mathrm{GHz}$ с точностью, обусловленной погрешностью измерения значения диэлектрической проницаемости.

При экспериментальном измерении коэффициента отражения в диапазоне $78-81 \mathrm{GHz}$ образец исследуемого материала в виде плоской пластины толщиной $3 \mathrm{~mm}$ с металлизацией на одной стороне был помещен вплотную к раскрыву прямоугольного рупора П6-135. Затем в пакете трехмерного электромагнитного моделирования была создана эквивалентная модель рупора с раскрывом

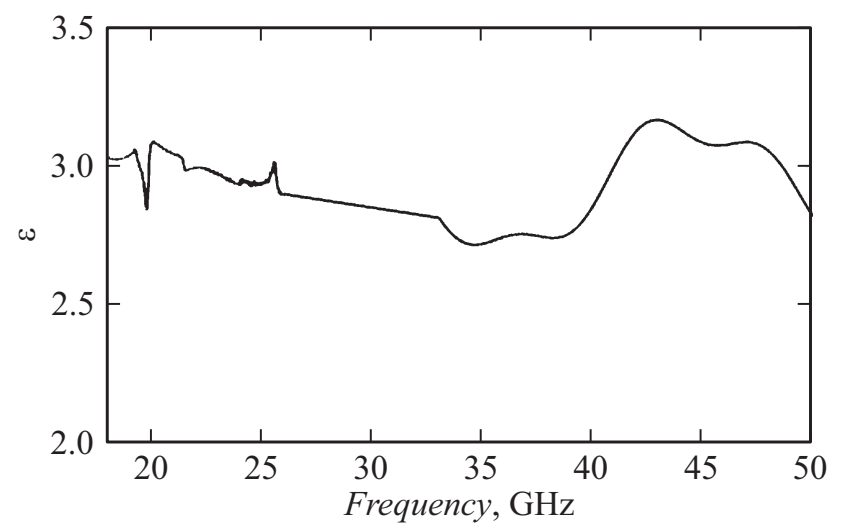

Рис. 2. Диэлектрическая проницаемость образцов Технотер A-CB30-T-20.

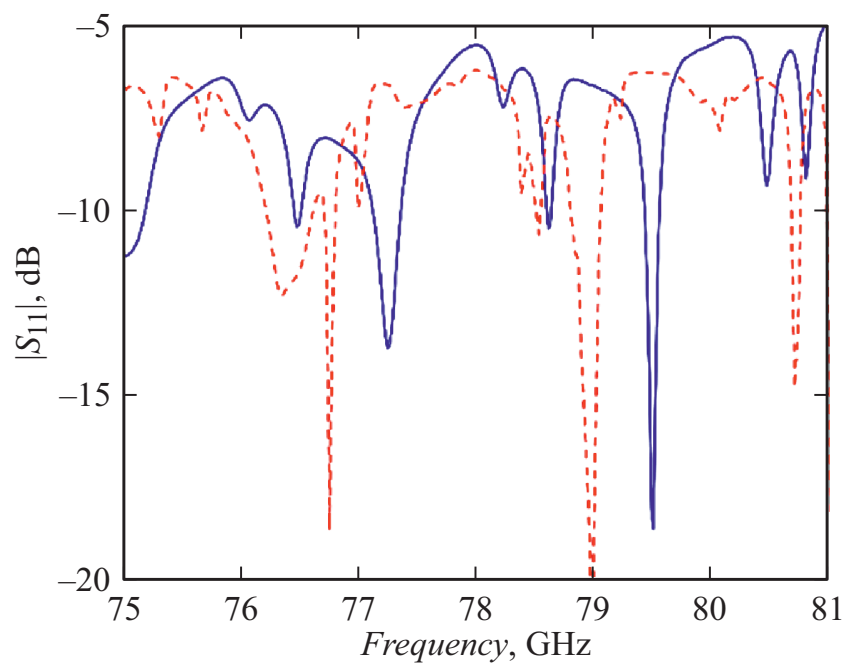

Рис. 3. Сравнение результатов моделирования электродинамических характеристик (коэффициента отражения) крышки радара, изготовленной из Технотер А-СВ30-Т-20 (штриховая линия), и измерения для образца материала с использованием векторного анализатора цепей (сплошная линия). 
$21 \times 17 \mathrm{~mm}$, вплотную к которому примыкает модель исследуемого образца, для которого диэлектрическая проницаемость во всем диапазоне анализа равна 3. Сравнение полученных в ходе экспериментального исследования и моделирования результатов измерения коэффициентов отражения приведено на рис. 3.

Сравнение результатов экспериментального исследования и моделирования показывает возможность использования результатов измерения диэлектрической проницаемости на частотах, меньших рабочего диапазона проектируемого устройства. Результаты анализа спектра диэлектрической проницаемости показывают, что материал Технотер А-СВ30-Т-20 можно использовать при производстве радиопрозрачных укрытий.

\section{Благодарности}

Авторы благодарят Д.Г. Лисиенко за содействие в проведении химического анализа образцов исследования.

\section{Финансирование работы}

Работа выполнена при финансовой поддержке Министерства науки и высшего образования РФ в рамках соглашения № 075-11-2019-052 от 13.12.2019 с Научнопроизводственным объединением автоматики им. академика Н.А. Семихатова по комплексному проекту „Создание высокотехнологичного производства высокочастотного радара, предназначенного для использования в составе интеллектуальных систем помощи водителю, систем автоматического управления беспилотных транспортных средств и систем интеллектуального земледелия“ при участии ФГАОУ ВО „Уральский федеральный университет им. первого Президента России Б.Н. Ельцина“ в части выполнения научно-исследовательских, опытно-конструкторских и технологических работ.

\section{Конфликт интересов}

Авторы заявляют, что у них нет конфликта интересов.

\section{Список литературы}

[1] https://www.continental-automotive.com/getattachment/ 99443083-31fb-4345-9b84-6a02707041d4/ARS404-21 _datasheet_en_170707_V07.pdf

[2] http://polimpartner.by/wp-content/uploads/2016/12/Tehnoter_ A-SV30-T.pdf

[3] В.И. Альперин, Н.В. Корольков, А.В. Мотавкин, С.Л. Рогинский, В.А. Телешев, Конструкционные стеклопластики (Химия, М., 1979), с. 178-181.

[4] А.А. Беляев, А.М. Романов, В.В. Широков, Е.М. Шульдешов, Тр. ВИАМ, № 5 (2014). dx.doi.org/ 10.18577/23076046-2014-0-5-6-6

[5] A.I. Malkin, N.S. Knyazev, CEUR Workshop Proc., 1814, 45 (2017). 